\title{
Coastal water environment regulation and simulation based on tidal power control
}

\author{
Hua Wang ${ }^{1, a}$, Wei Xu${ }^{1}$, Pei Liu' ${ }^{1}$ and Jinhe $\mathrm{Zhu}^{1}$ \\ ${ }^{1}$ Department of River \& Coastal Engineering of The Pearl River Hydraulic Research Institute, 510000 Guangzhou City, China
}

\begin{abstract}
As the carrier of water resources, water environment and water ecology, river course is very important to human and ecological environment in coastal areas. The rapid economic development of coastal areas needs to take into account the improvement of regional water environment in order to achieve a higher level of development. The characteristics of coastal water environment are closely related to tidal fluctuation. It is an important direction for coastal water control to improve the water environment and restore the self-purification capacity of the river by guiding and draining the tidal power. In this paper, the YACHONG River Basin, which borders Macau and Zhuhai, is selected as the study area. The semiexchange period and water exchange rate are taken as the main evaluation indexes. The water quantity and quality model is used to simulate the scenario model and analyze the effect of water diversion and drainage regulation in different tidal periods. The results show that, compared with the drainage dispatch during spring tide, the drainage dispatch during neap tide prolongs the water exchange time, and the effect of water exchange is obviously better than that during spring tide. The research results of this paper provide reference for water environmental regulation in coastal area.
\end{abstract}

\section{Introduction}

Coastal areas are close to the sea, with large population and developed economy. They are the most convenient region for overseas exchanges, trade and cross-border cooperation, and their geographical locations are very important. However, the economic development often took the water environment as the cost or ignored the regional water environment in the region, resulting in the deterioration of the water environment in the coastal region. The water load is serious and exceeds the selfpurification capacity, which has become a major water environmental problem in the region ${ }^{[1-2]}$.

In order to improve the water environment in coastal area, related researches were carried out successively. Coastal areas are affected not only by upstream runoff, but also by ocean tides. Pollutants entering the river channel show the state of reciprocating flow under the action of tides, which can easily lead to the accumulation of the pollution. The regional water environment features are closely related to tidal fluctuation. Combined with the water quality situation of the coastal area, through the regulation of estuary sluice, water diversion at spring tide and drainage at neap tide, the self-purification capacity of river water can be gradually restored and the water environment quality of the region can be improved. Therefore, the improvement of coastal water environment by drainage scheduling has been widely concerned ${ }^{[3-4]}$.

In research of diversion and drainage scheduling, there are many subjects, such as diversion water quality, diversion water quantity, and regional diversion, but few literatures involve the relationship between the effect of water diversion and drainage scheduling in different tidal periods and different frequency of water transfer. Drainage scheduling in coastal areas is closely related to changes in tidal dynamics, so additional studies are needed ${ }^{[5-7]}$.

\section{Material and methods}

\subsection{Material}

The study area is located in the YACHONG river basin at the junction of Macao and Zhuhai in GuangdongHong Kong-Macao Greater Bay Area. The Inner Harbour waters are linked to the Qianshan River Channel of Zhuhai, and are remitted into Wanchai River. A sluice gate is built at the downstream of the YACHONG River estuary, which is normally closed to maintain the landscape level of the YACHONG River at 0.8 meters. When the water quality of the YACHONG River is poor, the gate is opened at the ebb to drain to 0.3 meters, and then closed the gate.

The tidal level data used in this research were measured by the Macao Inner Harbour Tidal Level Station (1924-2017), which is $2.2 \mathrm{~km}$ away from the outlet of the YACHONG River. River section data are based on planning cross-section data.

\subsection{Methods}

a Corresponding author: wanghua@pearlwater.gov.cn 


\subsubsection{Evaluating indicator}

How to evaluate the effect of water exchange in the process of water exchange is the main issue we are concerned about. According to the relevant research and literature results, the main evaluation factors are semiexchange period and water exchange rate ${ }^{[8-9]}$. The definition of semi-exchange period and water exchange rate is as follows.

The semi-exchange period reflects the water exchange capacity of different sections of the river. In this paper, the conservative material is used as a tracer to calculate the time needed to reduce the conservative material content by half at a certain section of the river.

Water exchange rate reflects the water exchange capacity of each section. During the process of rising tide and falling tide, the water of the river and the water of the sea constantly mix, and the water after mixing is transported to the sea. The above process is water exchange, and the formula for water exchange rate is as follows.

$$
R(r, l, t)=\left(C\left(r, l, t_{0}\right)-C(r, l, t)\right) / C\left(r, l, t_{0}\right) * 100 \%
$$

Letter $r$ refers to the river, $l$ refers to mileage, $t$ refers to time. The three variables involved in Eq. (1) are initial concentration of a channel $C\left(r, l, t_{0}\right)$, instantaneous concentration of a channel $C(r, l, t)$, instantaneous water exchange rate in a certain channel $R(r, l, t)$.

\subsubsection{Mathematical model and parameter setting}

The change of concentration of conservative substances in the drainage process of the YACHONG River is simulated by MIKE11 HD and MIKE11 AD.

MIKE11 HD uses the Saint-Venant equations, which are composed of continuity equation of mass conservation and momentum equation of conservation of energy. The six point implicit scheme is used in the difference scheme, and the chase method is used in numerical calculation. The basic equations are as follows.

$$
\begin{gathered}
B \frac{\partial Z}{\partial t}+\frac{\partial Q}{\partial x}=q \\
\frac{\partial Q}{\partial t}+\frac{\partial}{\partial x}\left(\beta \frac{Q^{2}}{A}\right)+g A\left(\frac{\partial Z}{\partial x}+S_{f}\right)+u_{l} q=0
\end{gathered}
$$

Variables involved in Eq. (2) and (3) are average water level of section $Z$, section flow $Q$, water area $A$, water surface width $B$, distance $x$, time $t$, side inflow $q$, momentum correction factor $\beta$, acceleration of gravity $g$, frictional slope $S_{f}$, which is calculated by Manning formula, the component of the lateral outflow velocity in the main stream direction on the unit flow $u$.

According to the hydrodynamic conditions generated by MIKE HD, the convection diffusion equation is applied to calculate. The basic equation is as follows.

$$
\frac{\partial C}{\partial t}+u \frac{\partial C}{\partial x}=\frac{\partial}{\partial x}\left[E_{x} \frac{\partial C}{\partial x}\right]-K C
$$

Variables involved in Eq. (4) are concentration of matter $C$, average velocity of river $u$, convection diffusion coefficient $E_{x}$, first order attenuation coefficient of matter $k$.

According to the cross-section form of YACHONG river and the relevant research results of Pearl River Estuary, the roughness of the river is $0.02^{[10]}$.

\subsubsection{Simulation scenario}

The influence of different tidal periods on the effect of diversion and drainage is studied by controlling the amount of diversion and drainage with a single variable method. To this end, two scenarios are set up ${ }^{[11-12]}$.

The first scenario is that the gate is opened for drainage during falling tide, the water level of the river reaches 0.3 meters and the gate is closed. During rising tide, the gate is opened, the water level of the river reaches 0.8 meters and the gate is closed. The tidal level boundary takes the tidal level process during the spring tide.

The first scenario is that the gate is opened for drainage during falling tide, the water level of the river reaches 0.3 meters and the gate is closed. During rising tide, the gate is opened, the water level of the river reaches 0.8 meters and the gate is closed. Tidal level is the process of tide level during neap tide.

Under the two scenarios, the initial conserved matter concentration in the YACHONG River was $1 \mathrm{mg} / \mathrm{l}$ and the conserved matter concentration in the outer sea was $0 \mathrm{mg} / \mathrm{l}$.

\section{Results}

\subsection{Semi-exchange period}

During the dispatch of spring tide period, the characteristics of semi-exchange period of each reach are as follows. The semi-exchange period of upper reaches of the YACHONG river is about $72 \sim 74 \mathrm{~h}$, the semiexchange period of middle reaches of the YACHONG river is about $44 \sim 67 \mathrm{~h}$, and the semi-exchange period of lower reaches of the YACHONG river is basically within $24 \mathrm{~h}$.

During the dispatch of neap tide period, the characteristics of semi-exchange period of each reach are as follows. The semi-exchange period of upper reaches of the YACHONG river is about $44 \sim 47 \mathrm{~h}$, and the semiexchange period of middle reaches of the YACHONG river is about $14 \sim 37 \mathrm{~h}$, and the semi-exchange period of lower reaches of the YACHONG river is about $13 \mathrm{~h}$.

\subsection{Water exchange rate}

During the dispatch of spring tide period, the water exchange rate of each section is as follows. The water exchange rate of the first dispatch is $33 \%$, which means that the total amount of conservative material of the river is $67 \%$. The water conversion rate of the river reached $54 \%$ after two times of dispatch, and the remaining conservative material accounted for $46 \%$ of the total. 
The water exchange rate reached $67 \%$ after three times of dispatch and $77 \%$ after four times of dispatch.

The characteristics of water exchange rate in different sections during neap tide dispatching are as follows. The water exchange rate of the YACHONG River under the first dispatch is $50 \%$, which means that the total amount of conservative material in the YACHONG River is $50 \%$. The water exchange rate of the river reached $72 \%$ after two times of dispatch, and the remaining conservative material accounted for $28 \%$ of the total. Water exchange rate reached $84 \%$ after three times of dispatch and $91 \%$ after four times of dispatch.

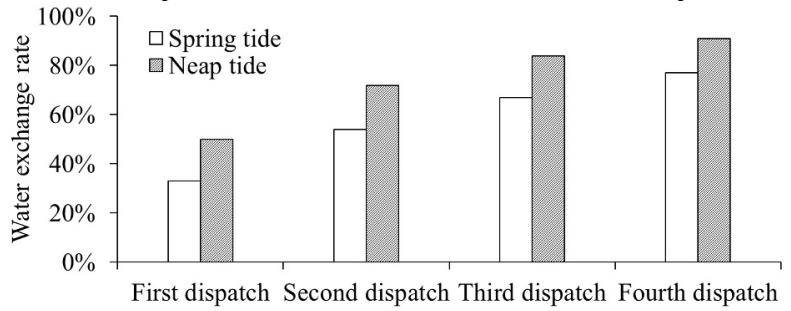

Fig 1. Water exchange rate chart.

\section{Discussion}

\subsection{Analysis of the characteristics of Semi- exchange period with time}

There is a close relationship between the variation of YACHONG river water quality and tidal characteristics. According to the concentration variation diagram of conservative substances (Fig. 2), the drainage regulation has a great influence on the concentration of conservative substances in YACHONG River. From the range of the concentration of conservative substances changing with time, the variation amplitude of the lower reaches of YACHONG River is the largest, followed by the middle reaches, and the change is the smallest in the upper reaches. The main reason is that the upper reaches are far away from the estuary, less affected by tidal dynamics, and the concentration of conservative substances changes more gently. The middle and lower reaches are greatly influenced by tidal power, and the change of the concentration of the conservative substance is very obvious. From the trend of concentration variation along the river, the concentration of conservative substances in the upper reaches has been slowly decreasing. The concentration of conserved substances in the middle and lower reaches decreases first and then increases. The main reason is that when the sluice is opened, and the water of YACHONG river exchanges with the clean water of the offshore sea, and the downstream water is replaced first. Conservative substance concentration drops rapidly, and because of the weak hydrodynamic force in the upper reaches, the concentration of conservative substances decreases slightly and keeps high consistency all the time. Conservative substances diffuse from the upper reaches of the YACHONG River to the lower reaches of the YACHONG river under the action of concentration gradient, and conservative substances concentration increases in the lower reaches.
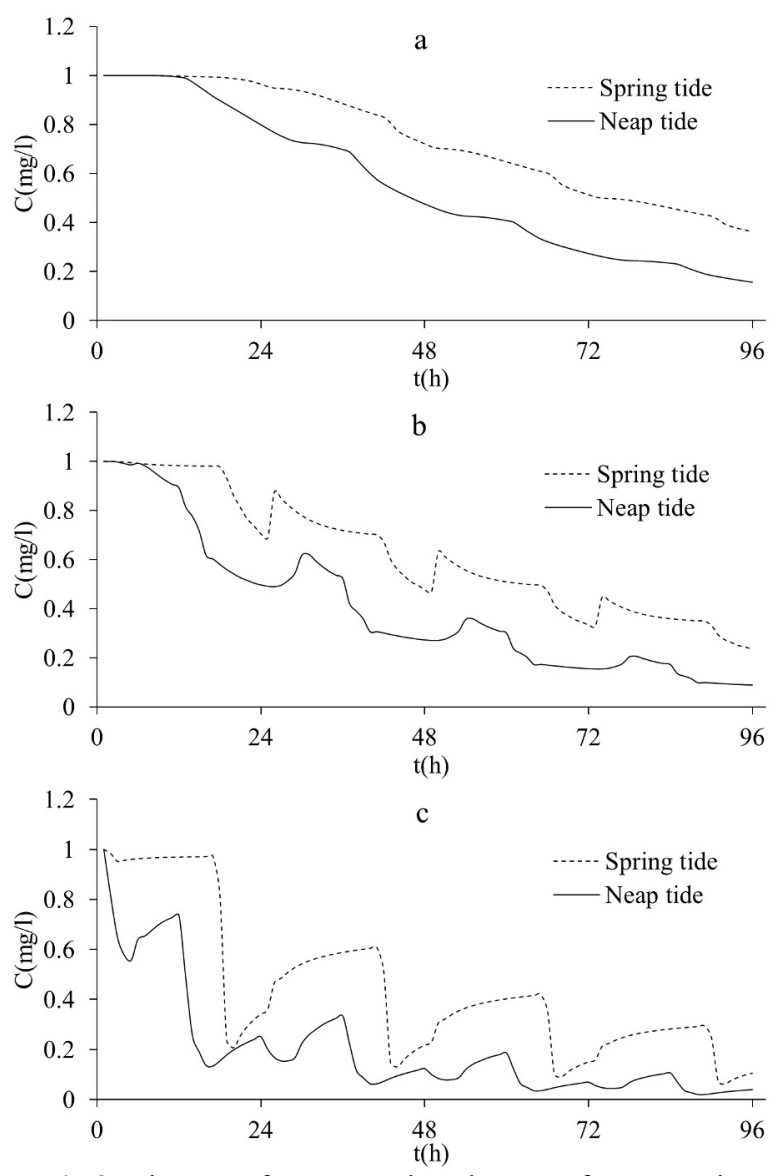

Fig 2. Diagram of concentration changes of conservative substances (Fig. a shows the concentration variation of conservative substances in the upstream. Fig. $b$ shows the concentration variation of conservative substances in the middle stream. Fig. $\mathrm{c}$ shows the concentration variation of conservative substances in the downstream.)

It can also be seen from the diagram that the concentration of conservative substances in spring tide period is higher than that in neap tide period. The convection will be stronger in the spring tide period than in the neap tide period, and the effect of water exchange with high velocity will be worse. Obviously, the convection of conservative materials does not play a dominant role in this particular boundary condition. When diverting water, there is a concentration difference between the upstream and downstream of the conservative substance, the time of diverting water is longer in the neap tide period, and the diffusion time of the conservative substance is longer, which makes the concentration of the conservative substance decrease more.

\subsection{Analysis of spatial variation characteristics of conservative substance concentration after scheduling}

The concentration of conservative substances in the YACHONG River can be reduced by controlling the tidal dynamics. Based on the simulation results, the variation of the concentration of conservative substances in the YACHONG River after each dispatch (Fig. 3). It can be seen from the diagram that the water exchange at the YACHONG river estuary gate is faster, and the 
upper reaches are farther away from the estuary, and the water exchange is slower. When the first dispatch is completed, the YACHONG estuary is close to the sea, and the water exchange begins at first. The concentration of conservative substances decreases by about $70 \%$, while the concentration of upstream conservative substances changes slowly. The concentration of conservative substances decreases by only about $20 \%$. The concentration difference of conservative substances in the river is large. When the second dispatch is completed, the concentration of conservative substances in the lower reaches of YACHONG River decreases slightly, but the concentration of conservative substances is at a lower level. The upstream decline is between $10 \%$ $\sim 20 \%$, but the concentration of the conservative substance is still very high. At the completion of the fourth dispatch, the concentration of the conservative substance changed slowly along the river.

It can also be seen from the diagram that the concentration of conservative substances in spring tide period is higher than that in neap tide period regulation. And the concentration of conservative substances along the YACHONG River is very close between after the second dispatch in the spring tide period and the first dispatch in the neap tide period. The concentration of conservative substances along the YACHONG River is very close between after the third dispatch in the spring tide period and the second dispatch in the neap tide period. This indicates that the prolongation of water exchange time is conducive to water exchange.
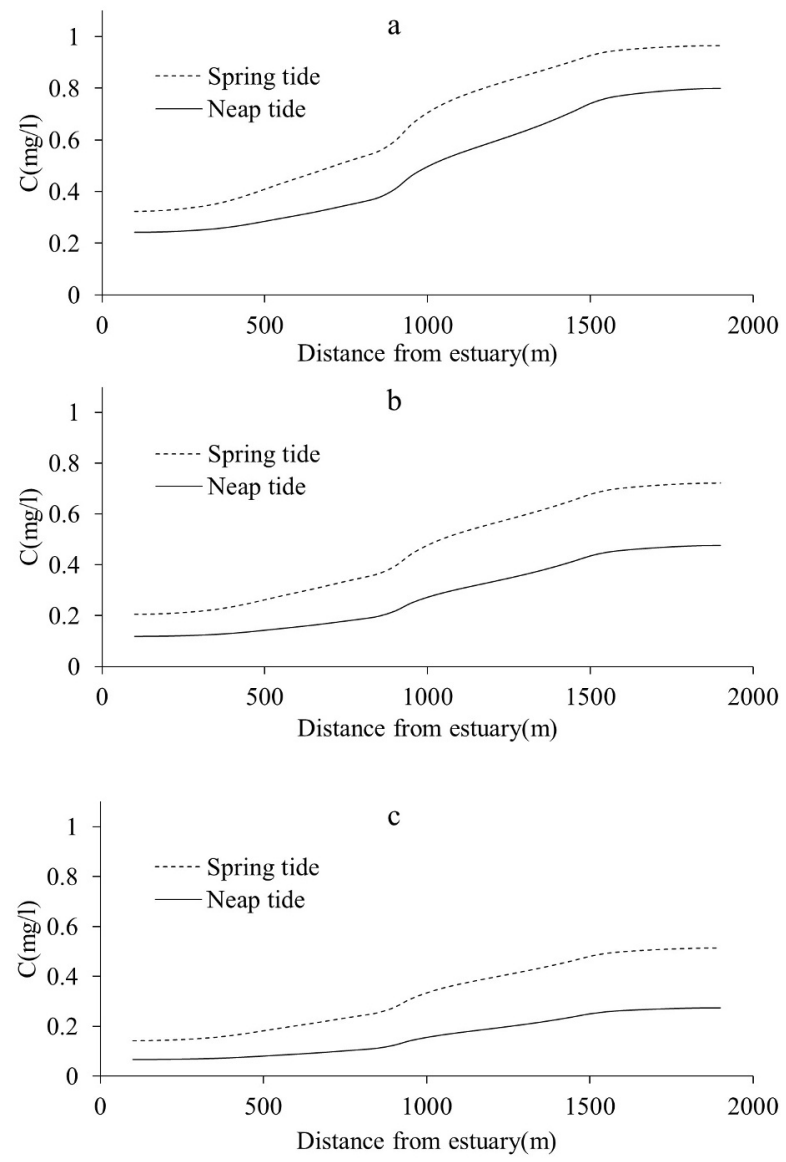

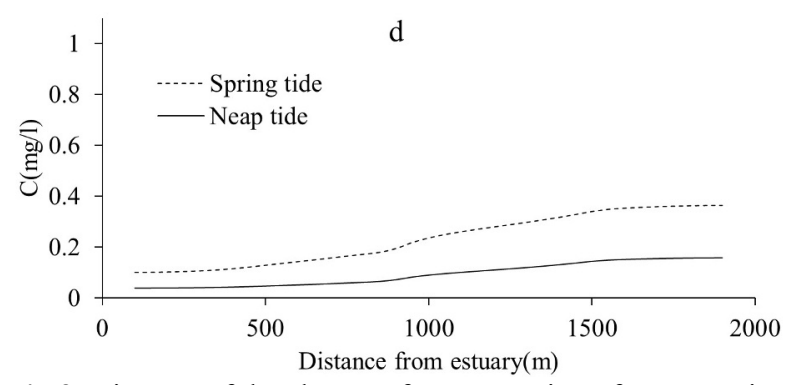

Fig 3. Diagram of the change of concentration of conservative substances along YACHONG River. (Fig. a is diagram of the change of concentration of conservative substances along YACHONG river after the first dispatch. Fig. $\mathrm{b}$ is diagram of the change of concentration of conservative substances along YACHONG River after the second dispatch. Fig. $\mathrm{c}$ is diagram of the change of concentration of conservative substances along YACHONG River after the third dispatch. Fig. $d$ is

diagram of the change of concentration of conservative substances along YACHONG River after the fourth dispatch.)

\section{Conclusions}

YACHONG River is located in the Pearl River Delta area. The upstream is not connected with other waters. There is a gate between the downstream and the sea. It is usually closed to maintain the landscape water level of 0.8 meters in the YACHONG River. When the water quality of the YACHONG River is poor, the water quality can be improved through drainage dispatch. Under the action of tide, the flow in the river is reciprocating flow through the gate control, and the dispatch effect is greatly affected by the tidal characteristics.

In order to explore the effect of diversion and drainage dispatch in different tidal periods, two scenarios of diversion and drainage dispatch are set up according to single variable method, which are diversion and drainage dispatching in spring tide period and diversion and drainage dispatching in neap tide period. The results of numerical simulation show that, compared with diversion and drainage during spring tide period, diversion and drainage during neap tide period can prolong the time of water exchange, and the effect of water exchange is obviously better than that of diversion and drainage dispatch during spring tide period. The results of this study provide a theoretical reference for water environmental regulation in the coastal area.

\section{References}

1. Guangbai Cui, Xing Chen, Long Xiang, Qicheng Zhang, Qin Xu. Journal of Hydraulic Engineering 48(12), 1429-1437 (2017)

2. Xing Chen, Qin $\mathrm{Xu}$, Xinyue He, Guangbai Cui, Wanying Lu. Water Resources Protection 32(2), 7781 (2016)

3. Guanglian Liu. Study on the landscape water requirement and the period of exchanging water of the estuarine wetland parks (Shandong Jianzhu University, Shandong Province, 2010) 
4. Ying Li, Kang Liang, Huajun Lou, Zhan Xin, Zheng Zhang. South-to-North Water Transfers and Water Science \& Technology 14(3), 48-54 (2016)

5. Xiuju Zhang, Kaisen Ding, Kai Yang. Water Resources and Power 2017(1), 31-34 (2017)

6. Wenxue He, Bing Zhou, Dongyun Chen,Chaqing Li,Qihua Xie. China Water \& Wastewater 28(17), 63-67 (2012)

7. Guiquan $\mathrm{Xu}$, Changtai Chen, Yingzhou Tang. Water Resources Protection 2013(6), 80-84 (2013)

8. Hao Wei, Tian Tian, Feng Zhou, Liang Zhao. Journal of Ocean University of Qingdao 32(4), 1423 (2002)

9. Zhenhua Chen, Changshui Xia, Fangli Qiao. Acta Oceanologica Sinica 39(3), 14-23 (2017)

10. Wenlong Chen, Yang Fang. Technical guidelines for flood control in Pearl River Delta and estuarine areas and case studies (China Water \& Power Press, Beijing City, 2014)

11. Shengwei Gan, Hongju Zhang, Yunyun Feng. Yangtze River 43(5), 72-75 (2012)

12. Zulan Mo. Research on controlling optimal model of pumps and sluices based on water purification capacity (Zhejiang University, Zhejiang Province, 2014) 